\title{
Analysis of The Impact of Electricity Market on Economic Growth in Nigeria.
}

\author{
David A. Samuel ${ }^{1 *}$, Enitan Wale-Odunaiya ${ }^{2}$ \\ 1. Department of Economics, Veritas University, Abuja. \\ 2. Department of Economics, Veritas University, Abuja \\ *Email: adesam62@gmail.com
}

\begin{abstract}
This work examined the impact of electricity market on economic growth in Nigeria between 1971 and 2014. The supply of electricity affects the prices of outputs from the firms and industries while the demand for electricity affects how much can be supplied and the price of electricity which in turn affects final products produced. The variables used for electricity supply was a disaggregated sources of electricity generation, like oil, hydroelectric and gas, and the demand for electricity was also disaggregated into industrial and residential. Autoregressive Distributed Lag Model was employed after the unit root test showed mixed order of integration. The findings revealed that there was a long run relationship and it is significant. But the short run relationships were not significant although they all showed positive relationship with growth. It was therefore recommended that the power sector be more liberalized for more private participation both at the generation, transmission and distribution levels.
\end{abstract}

Key Words: Energy, Electricity, Economic Growth, Demand and Supply of Electricity

DOI: $10.7176 / \mathrm{JESD} / 12-20-08$

Publication date:October $31^{\text {st }} 2021$

\subsection{Introduction}

The growth and development of any economy today is heavily dependent on the supply and consumption of electricity, for commercial, domestic, social and productive activities. In other words, electricity supply and demand play important roles in the social, economic and technological advancement of every nation. Electric power is needed in the production process and therefore can be considered as one of the major factors that affects production. Electricity market in this work refers to both the demand and supply of electricity. It is a known fact that any change in the quality and quantity of electricity supply available for the production of goods and services will greatly influence production and evidently the level of output of industries. On the other hand, the level of demand for electricity affects the availability for use both for industrial and domestic purposes and that also affects the price of supply which in turn affects the cost of production and final price of goods and services. Inadequate and irregular electricity supply and its effect on business enterprises especially small and medium enterprises has been a subject of concern in the third world or developing countries. Electricity consumption is the total amount of electricity (kwh) that is consumed in a given economy at a particular time and it determines how much of the supply of electricity that is actually used by consumers. Electricity supply is part of the economic infrastructure mostly needed for increased performance and output of firms. The interrelationship between electricity supply and productivity and social services has been asserted to be very strong (Sambo, Garba, Zarma, and Gaji, 2010).

Most studies have investigated the causal relationship between electricity consumption and economic growth and found that there is a unidirectional causality running from electricity consumption to growth (Iyke, 2014; Kasperowicz, 2014). This result supports the growth hypothesis that an increase in energy consumption leads to increase in economic growth. Some others support the conservative hypothesis, which states that economic growth leads to increase in electricity consumption (Faisal, Tursoy and Ercantan, 2017). While some other works showed evidence of feedback hypothesis, which indicates evidence of bi-directional causality between energy consumption and economic growth (Ogundipe and Akpata, 2013).

The small and medium enterprises form the bulk of the production sub-sector in the Nigerian economy (Ariyo, 1999; Ihua, 2005), yet, a major factor that could aid their productive performance has been left practically unattended. Electricity supply gap has been of great concern over the past few decades. In 2003, the Energy 
Commission of Nigeria projected that the country needed to generate at least $103,000 \mathrm{MW}$ by 2020 if it would attain the required full economic industrialisation (Sambo, Garba, Zarma and Gaji, 2010) but so far, only about $5,150 \mathrm{MW}$ has been the highest electricity supply generated in the country since 1980 and according to Awoyinfa (2018) the country will need about $180,000 \mathrm{MW}$ to enjoy a stable electricity supply.

Consequent upon this irregular supply of electricity, the country constantly experiences a decline in production and profitability. The work of Adenikinju (2003) showed that there exists a strong relationship between the amount of electricity supplied and the performance of business enterprises. Efficiency of electricity supply from the national grid brings down the running and overhead costs of businesses and that leads to higher profitability in the long run. Failure to provide adequate electricity makes the firms spend the money that could have been reinvested while trying to secure an alternative source of power, which are not cost effective on productivity, simply because of additional maintenance costs. Demand for electricity far outweighs the supply in Nigeria, due to inadequate and epileptic supply.

Electricity was first produced in Lagos, Nigeria in 1896 fifteen years after it was introduced in England (Sambo, 2008). The age of electricity in Nigeria has not translated to efficiency and sufficiency in production. The management of electricity supply has transited from one organization to the other. The first was the Electricity Corporation of Nigeria ( ), others were Native Authorities and Nigeria Electricity Supply Company (NESCO) that had license to produce at particular locations in the country. Later we had the Niger Dam Authority (NDA) which was to construct and maintain the dams in river Niger. All energy produced by NDA was sold to ECN that was being sold to end-users.

Both the ECN and NDA were amalgamated in 1972 to form the National Electric Power Authority (NEPA). This body became the government monopoly that managed electricity supply across the nation. Just to ensure a hitch free transmission of the electricity generated, NEPA had to install about 11,000Kilometers of transmission lines across the nation. On a similar note, several installations of transformers and other relevant facilities were carried out just to ensure adequate transmission and distribution of electric power throughout the country. All these efforts could not address the power shortage and frequent outages, but rather getting worse. This cumbersome generation, transmission and distribution process led the current phase of reform which started with the formation of PHCN. The power reform bill was signed into law by March 2005, which stipulated the possibility of private companies to participate in electricity generation, transmission, and distribution. The Act also provided for the establishment of the Nigeria Electricity Regulatory Commission (NERC) to monitor and regulate the power sector as it undergoes reform.

Despite all these transitions, electricity supply was still abysmally low and government then charted a road map for improvement in the supply by the Power Sector Reform of 2010

"To meet our Vision 20:2020 target of 40,000MW will require investments in power generating capacity alone of at least US\$3.5 billion per annum for the next 10 years. Correspondingly large investments will also have to be made in other parts of the supply chain (i.e. the fuel-to-power infrastructure and power transmission and distribution networks). These sums cannot and will not be funded and directed by the Federal Government. Rather, central to the development of the sector will be the need to incentivize the private sector to partner with government in this endeavor". (The Roadmap)

Despite all these reforms, the produced electricity continues to fall to as low as 3, 657MW as at April 2021 (Esiedesa, 2021). The challenge created by this continuous fall in supply is that it creates a supply gap in the market and that leads to consumers seeking alternative sources to power their machineries, homes or business and this consequently leads to higher production costs and the associated final goods' prices. It is this detrimental effect on the national productivity growth that this work is set out to investigate. Practically all the literatures on electricity and economic growth simply either looked at the demand or the supply side and their effects on economic growth. But this work investigated an integration of both the supply and demand side to see the net effect on economic growth in Nigeria.

This work is structured into five sections. Section two presents the review of available literatures, section three presents the theoretical framework and methodology. The findings and analysis of the work will be presented in section four while the summary and policy recommendations will be highlighted in section five. 


\subsection{Literature Review}

Lugman, Hag and Ahmad (2021) studied the role deficiency of quality and dependable electric power supply could have on the performance and competitive ability of firms in the developing economies especially in the South East Asian countries. The Stochastic Frontier methodology was employed in the analysis and the use of Ordinary Least Square and Beta regression were employed to estimate the parameters. The findings revealed that power outages led to a technical inefficiency of firms in South East Asian countries. It was therefore recommended that the countries concerned should embark on appropriate and adequate investment in the energy sector to enjoy a secure and reliable power supply in the countries and consequently increase in productivity and competitive capacity.

Abdisa (2018) examined the constraint that power supply unreliability has on productivity of firms in developing countries especially in Ethiopia between 2011 and 2015. The World Bank data was used to carry out the analysis and the findings revealed that firms' productivity were negatively affected and similarly increasing the production cost by 15 percent. It was discovered that the cost is higher for smaller firms because of the size of their output. This result was substantiated by the work of Cole, Elliot, Occhialli and Strobi (2018) on 14 countries in SubSaharan Africa. They were able to construct an instrument to represent the power outages dependent on the size of electric power produced by the hydro stations. Firm-level data from the World Bank Enterprise survey was used and the results revealed that there exists a negative relationship between firms' sales and power instability. It was further established that if other countries can reduce their power outages to the level obtained in South Africa, firms in these countries will increase their sales by 85.1 percent and climbing to about 117.4 percent for firms that do not use generators. It was therefore recommended that policies to increase output of electricity to stabilize the supply should be put in place these countries to boost both their productivity and sales.

Magongo and Sacolo (2018) studied the economic cost of power fluctuations in Eswatini, Swaziland. The work employed both direct and indirect cost method and using a binary logistic regression to estimate the coefficients, the findings showed that the industrial sector experienced the highest cost when compared with other sectors. The implication of this is that power outages increases the operating costs of the industries in this sector and that further weaken the profitability and long run productivity from this sector in the long run. The work therefore recommended that energy policies that could help to improve the generation of alternative energy sources should be designed to lower the cost of production and raise the standard of living.

Faisal, Tursoy and Ercantan (2017) investigated the relationship between energy consumption and GDP in Belgium between 1960 and 2012. Their study employed Autoregressive Distributed Lag model using TodaYamamoto for causality test. The result showed that there existed a long run relationship between the variables and that GDP positively affects the consumption of energy in the country. The result of the causality test showed that conservative hypothesis was confirmed between GDP and energy consumption. That is, causality runs from GDP to energy consumption. It was therefore recommended that policies that are based on conservation should be designed and implemented and that will avoid negative effect on economic growth.

Mezghani and Hedi (2016) in their study on electricity demand and economic growth in Saudi Ariabia between 1971 and 2010 employed the Time-varying parameters Vector Autoregressive (TVP-VAR) methodology for the analysis. The work showed that the model was suitable for the examination of the relationship between electricity consumption, real Gross Domestic Product and carbon emission. The study however discovered that the erratic electricity supply in the 1970s and 1980s must have affected the GDP negatively during that period. It was therefore recommended that policies to militate against such volatility of power supply should be designed to be able to stabilize the growth in GDP.

Okorie and Manu (2016) examined the causal linkage between electricity consumption and economic growth in Nigeria between 1980 and 2014. Vector Autoregressive (VAR) methodology and Johansen cointegration were employed and the results showed that there was a long run relationship between them. The findings also confirmed the growth hypothesis that causality runs from electricity consumption to growth. It was therefore recommended that generation of electricity should be increased through deliberate policies to further boost economic growth.

Iyke (2014) conducted an examination of the causal relationship between electric consumption and economic growth in Nigeria between 1971 and 2012. The work employed Vector Error Correction Mechanism and the findings revealed that there is causality running from electricity consumption to economic growth both in the short and long run. This finding supported the growth hypothesis. It was therefore recommended that policy that will enhance electricity generation should be designed and implemented to fast-track economic growth in the country. 
Kasperowicz (2014) did an investigation on the link between electricity consumption and economic growth in Poland between 2000 and 2012. The author first established the causality between them and then went ahead to estimation the production function using electricity as an input. The result showed that there existed a feedback hypothesis between them and the estimation of the production function showed that economic growth in Poland was heavily dependent on electricity.

Kareem, Hakeem, Kamilu and Bashir (2014) carried out an econometric analysis of electricity consumption and economic growth. The sources of electricity were disaggregated into oil, gas, hydroelectric and coal. The study covered the period between 1976 and 2011 and the methodology of regression and causality test were used. The findings revealed that only oil had a causality on GDP but it was also found that gas, hydroelectric and coal significantly affected GDP. Policies that could enhance the productivity of hydroelectricity and natural gas should be designed and implemented.

Omay, Hasanov and Ucar (2014) conducted an examination of the nonlinearity between energy consumption and economic growth in G7 countries. The work employed a nonlinear cointegration test and Panel Smooth Transition Vector Error Correction model and similarly used nonlinear Granger causality test. The findings revealed that causality between the variables depends on which phase of the business cycle the economy is operating in.

Ogundipe and Apata (2013) examined the nexus between electricity consumption and economic growth for Nigeria between 1980 and 2008 using Johansen Cointegration technique with the help of Cobb-Douglas production function. The Vector Error Correction Mechanism methodology was used and Pairwise Granger causality test was used to check the nature of causality between them. It was found that there existed a feedback hypothesis between the variables. The variables were found to be cointegrated and electricity consumption impacting economic significantly. It was therefore recommended that electricity generating agencies be strengthened for effectiveness and constant replacement of obsolete equipment needed to generate, transmit to avoid losses in transmission process.

\subsection{Theoretical Framework}

This work is hinged on the neo-classical growth model developed by Solow-Swan (1956). This theory asserts that using labour and fixing capital as inputs in the production process, productivity is increased at decreasing returns when there is no technological progress. But when technological progress is taken into consideration, it negates the tendency for decreasing returns. This theory employs a production function that is a function of the inputs of production, such as labour and capital specified in Cobb-Douglas production function of the type:

$$
Q_{t}=A K^{\alpha} L^{\beta}
$$

Where $\beta=1-\alpha, \mathrm{A}=$ Total factor productivity, $\mathrm{K}=$ capital input, $\mathrm{L}=$ labour input $\alpha$ and $\beta$ are output elasticities, $\mathrm{Q}=$ Output level.

\subsection{Methodology and Model Specification}

Adapting from the works of Kasperowicz (2014) and Ogundipe and Apata (2013) where they used electricity consumption as a factor of production and consequently an independent, this work incorporates both electricity consumption and supply as independent variables determining aggregate output in the economy. We can therefore express equation (3.1) as:

$$
Q_{t}=A K^{\alpha} L^{\beta} E L E S S^{\beta 1} E L E D D^{\beta 2}
$$

Taking the log linear of (3.2), we have:

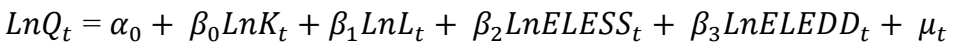

Where $\alpha, \beta_{s}=$ parameters to be estimated, ELESS $=$ Electricity supply, ELEDD $=$ Electricity demand, $\mu_{t}=$ error term satisfying the OLS assumptions. 
This work added value to the body of knowledge by disaggregating electricity supply into electricity production from oil, gas and hydroelectric sources. It also disaggregated electricity demand into residential and industrial. Incorporating the disaggregated variables, equation (3.3) then becomes:

$\mathrm{GDPGR}_{t}=\alpha_{0}+\beta_{0} \mathrm{ELEDD}_{t}+\beta_{1} \mathrm{ELEIND}_{t}+\beta_{2} \mathrm{ELERES}_{t}+\beta_{3} \mathrm{ELPOIL}_{t}+\beta_{3} \mathrm{ELEHP}_{t}+\beta_{3} \mathrm{ELEGS}_{t}+\mu_{t}$

Where GDPGR = GDP growth, ELEDD = aggregate electricity demand, ELEIND = electricity in the industrial sector, ELERES = electricity in the residential, ELPOIL = electricity produced from oil, ELEHP= electricity produced from hydroelectric power, ELEGS = electricity produced from natural gas,

The estimation technique will be determined by the outcome of the unit root tests. The unit root was carried out and the outcome showed that there is a mixture of order of integration $\mathrm{I}(0)$ and $\mathrm{I}(1)$. On the basis of this result, this work employed Autoregressive Distributed Lag (ARDL) Model with Bounds testing for cointegration employed for the cointegration test among the variables.

\subsubsection{ARDL Model Specification}

The unit root test was carried out and the results showed that the variables were integrated at both 1 and 0 , that is, I(1) and I(0). Consequently, this work employed the Autoregressive Distributed Lag (ARDL) Bounds Test to check for cointegration and if found, we estimated the long run model with Error Correction Model.

The generalized ARDL ( $\mathrm{p}, \mathrm{q})$ model is specified as below:

$$
Y_{t}=\alpha_{0 j}+\sum_{i=1}^{p} \partial_{j} Y_{t-1}+\sum_{i=0}^{q} \beta_{j} X_{t-1}+\varepsilon_{j t}
$$

The steps to estimate the ECM were as follows:

i. $\quad$ Establish the cointegration using Bounds testing

ii. If there is cointegration, choose appropriate optimal lag length.

iii. Estimation of the long run ARDL model

iv. Reparameterization of ARDL model into Error Correction Model

For an ARDL of this order (p, q1, q2, q3, q4, q5, $\left.\mathrm{q}^{6,} \mathrm{q}^{7}\right)$

The long run relationship for this work is also expressed as follows:

$\mathrm{GDPGR}_{t}=a_{01}+b_{11} \mathrm{GDPGR}_{t-1}+b_{21} \mathrm{ELEDD}_{t-1}+b_{31} \mathrm{ELEIND}_{t-1}+b_{41} \mathrm{ELERES}_{t-1}+b_{51} \mathrm{ELPOIL}_{t-1}+$ $b_{61}$ ELEHP $_{t-1}+b_{71}$ ELEGS $_{t-1}+e_{1 t}$

When there is cointegration, the Error Correction Model (ECM) is then specified as follows:

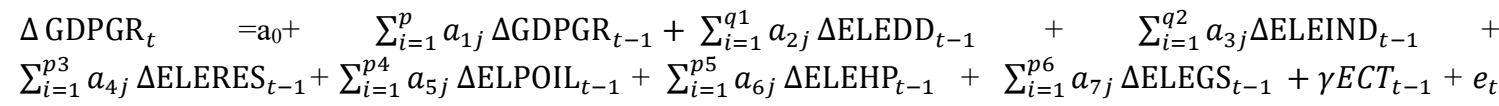

The Error Correction Model (ECM) can be derived from ARDL model through a simple linear transformation, which integrates short run adjustments with long run equilibrium without losing long run presence.

\subsection{Data and Source}

The data for this work is annual time series data spanning the period between 1971 and 2014. The ending date was due to availability of data. GDP growth and Electricity consumption, named as electricity demand were obtained from National Bureau of Statistics. Electricity consumption for industrial and residential were obtained from 
Power Holding Company of Nigeria (PHCN), Electricity produced from oil, hydroelectric power, and gas, were obtained from World Development Indicator of the World Bank.

\subsection{Presentation and Analysis of Results}

\subsection{Unit Root Test}

The stationary condition of the variables were tested using Augmented Dickey Fuller test method and it was found that there was a mixture of integration at 0 and 1 or I(0) and I(1) as presented in table 4.1. This test result suggested that the estimation method to be used is Autoregressive Distributed Lag (ARDL) model and using the Bounds testing for cointegration method. This method accommodates the estimation of time series data that are integrated of different order but not I(2).

Table 4.1: ADF Unit Root test results

\begin{tabular}{|l|l|l|l|l|l|l|l|}
\hline & At Level & & & \multicolumn{2}{|l}{ At First Difference } & & \\
\hline Variable & ADF stat & $\mathbf{5 \%}$ level & $\begin{array}{l}\text { Prob. } \\
\text { Value }\end{array}$ & ADF stat & $\mathbf{5 \%}$ level & $\begin{array}{l}\text { Prob. } \\
\text { Value }\end{array}$ & $\begin{array}{l}\text { Order of } \\
\text { Integration }\end{array}$ \\
\hline GDPGR & -5.96029 & -2.9314 & 0.0000 & & & & I(0) \\
\hline ELEDD & -1.29461 & -2.9314 & 0.6236 & -8.83752 & -2.93316 & 0.0000 & $\mathrm{I}(1)$ \\
\hline ELPOIL & -4.62041 & -2.9314 & 0.0005 & & & & $\mathrm{I}(0)$ \\
\hline ELEHP & -2.5147 & -2.9314 & 0.1191 & -8.42749 & -2.93316 & 0.0000 & $\mathrm{I}(1)$ \\
\hline LNELEIND & -3.46071 & -2.9314 & 0.0141 & & & & $\mathrm{I}(0)$ \\
\hline LNELERES & -2.97404 & -2.9314 & 0.0454 & & & & $\mathrm{I}(0)$ \\
\hline ELEGS & -1.66293 & -2.9314 & 0.4425 & -7.6279 & -2.93316 & 0.0000 & $\mathrm{I}(1)$ \\
\hline
\end{tabular}

Source: Author computed using Eviews 10

\subsection{Cointegration Test}

As a result of the unit root test, this work adopts the Bounds testing under Autoregressive Distributed Lag model to check if there is a long run relationship among the variables. The result is presented in table 4.2. Bounds test uses the F-test against the levels of integration. The null hypothesis is that there is no cointegration. The dicision rules are: If the F-statistic is lower than the lower bound value $\mathrm{I}(0)$ at the significant level of interest, we accept that there is no cointegration. But if the F-statistic lies between the lower bound and upper bound values, it is undecided. On the other hand, if the F-statistic is greater than the upper bound values, we reject the null hypothesis and conclude that there is cointegration. 
Table 4.2: Cointegration test using Bounds test

\begin{tabular}{|l|l|l|l|l|}
\hline \multicolumn{2}{|l|}{ F-Bounds Test } & & & \\
\hline \multicolumn{3}{|l|}{ Null Hypothesis: No Cointegration } & & \\
\hline & & $\ldots$ & & \\
\hline F-statistic & 20.12028 & $10 \%$ & 1.99 & 2.94 \\
\hline $\mathrm{k}$ & 6 & $5 \%$ & 2.27 & 3.28 \\
\hline & & $2.5 \%$ & 2.55 & 3.61 \\
\hline & & $1 \%$ & 2.88 & 3.99 \\
\hline
\end{tabular}

Source: Author computed using Eviews 10

Table 4.2 showed that the F-statistic (20.12) is higher than I(1) at all levels of significance, and that implies there is cointegration among the variables, in other words, all the variables have long run relationship and move together. On the basis of this result, the error correction model was estimated as displayed in table 4.3.

\section{3: Error Correction Model}

Model 3.6 was estimated after confirming cointegration among the variables. The process is to first estimate the long run as shown in model 3.5, extract the residuals and rename it as ECT and then regress the ECT variable along with the short run variables. The ECT is the long run representation in the Error Correction Model. The automatic lag selection under the ARDL chose lag one for all the variables.

\subsubsection{Short Run Analysis}

It was shown in table 4.3 that GDP growth lagged one period is positively related to current growth, but not significant. The result indicated that a 1 percent increase in the previous growth will stimulate current growth by about 8.9 percent.

Total electricity consumption is also positively related to growth but not significant. The result showed that a unit increase in total demand for electricity leads to a 2.6 percent increase in economic growth.

Industrial consumption of electricity is also positively related to economic growth but not significant. It showed that a 1 percent increase in industrial consumption will lead to about 684 percent increase in economic growth. That is to say that industrial consumption of electricity has a high potential of raising economic growth if their supply can be made regular. The impact of their electricity consumption is so large that many companies have relocated out of the country due to instability in power supply. 
Table 4.3: Error Correction Model

\begin{tabular}{|c|c|c|c|c|}
\hline \multicolumn{4}{|c|}{ Dependent Variable: D(GDPGR) } & \multirow[b]{2}{*}{ Prob. } \\
\hline Variable & Coefficient & Std. Error & $\mathrm{t}$-Statistic & \\
\hline $\mathrm{C}$ & 0.328976 & 0.806051 & 0.408132 & 0.6858 \\
\hline $\mathrm{D}(\operatorname{GDPGR}(-1))$ & 0.0886 & 0.187836 & 0.47169 & 0.6403 \\
\hline $\mathrm{D}(\operatorname{ELEDD}(-1))$ & 0.02573 & 0.062532 & 0.41139 & 0.6834 \\
\hline $\mathrm{D}(\mathrm{LNELEIND}(-1))$ & 6.841876 & 3.289393 & 2.079981 & 0.0454 \\
\hline D(LNELERES(-1)) & 5.17952 & 5.304882 & 0.97637 & 0.336 \\
\hline D(ELPOIL(-1)) & 0.163037 & 0.339697 & 0.47995 & 0.6344 \\
\hline $\mathrm{D}(\operatorname{ELEHP}(-1))$ & 0.069535 & 0.285453 & 0.243597 & 0.8091 \\
\hline $\mathrm{D}($ ELEGS(-1)) & 0.04161 & 0.231075 & 0.18007 & 0.8582 \\
\hline $\mathrm{ECT}(-1)$ & -1.12291 & 0.246 & -4.56467 & 0.0001 \\
\hline R-squared & 0.581253 & & & \\
\hline Adjusted R-squared & 0.479738 & & & \\
\hline F-statistic & 5.725812 & & & \\
\hline Prob(F-statistic) & 0.000135 & & & \\
\hline Durbin-Watson stat & & 1.882677 & & \\
\hline
\end{tabular}

Source: Author computed using Eviews 10

Residential consumption is also positively related to economic growth but not significant. The coefficient showed that a 1 percent increase in residential consumption will raise economic growth by about 518 percent. That also revealed how significant demand for electricity in the homes is on economic growth. This growth potential is lost to alternative power generation being served by either generator or renewable power sources.

Electricity produced from oil is also positively related to economic growth but not significant. The coefficient showed that a 1 percent increase in the oil powered electricity will increase economic growth by 16.3 percent.

Hydroelectricity has a positive relationship with economic growth but also not significant. The coefficient showed that a unit increase in its production will generate about 7 percent increase in economic growth.

Electricity from natural gas is also positively related to growth but not significant. An increase in electricity from gas by 1 percent will lead to about 4 percent increase in economic growth.

All these sources of electricity production have the potential of boosting the GDP growth if they can be better improved and made to perform more optimally. Nigeria as an oil producing nation should not suffer in any way from electricity generation considering the abundance of a mixture of energy sources endowed in the country. All these short run results indicated that none of the variables can influence economic growth in the short run even though they all have positive relationship with growth. 


\subsubsection{Long Run analysis}

It had been established that there existed a long run relationship among the variables. This was confirmed by the coefficient of the error correction term. This coefficient corrects disequilibrium in the short run. The conditions for its relevance are: The coefficient must be negative and statistically significant. The coefficient $(-1.123)$ with a p-value of 0.0001 showed that the long run relationship is established. The coefficient showed that disequilibrium is corrected in the long run at the speed of adjustment of 112 percent. That implies that the model will converge at that speed of 112 percent.

Although the short run relationship is not strong, but there is a strong long relationship and it is understandable. Supply of and demand for electricity may not really have any strong short run effect on productivity but the long run impact will be tremendously significant.

\subsection{Residual Diagnostics}

In order to confirm if the assumptions of Ordinary Least Squares (OLS) are satisfied, the residual of the model was subjected to some diagnostic for serial correlation, heteroscedasticity and normality test.

Table 4.4: Residual Diagnostic tests

\begin{tabular}{|l|l|}
\hline & \\
\hline Breusch-Godfrey Serial Correlation LM Test & 0.2200 \\
\hline Heteroskedasticity Test: Breusch-Pagan-Godfrey & 0.5722 \\
\hline & \\
Jarque-Bera normality test & 0.7550 \\
\hline
\end{tabular}

Source: Author computed using Eviews 10

Table 4.4 showed that the model is free from serial correlation with a p-value of 22 percent. This also is confirmed by the D-W statistic in the model. The residuals are also homoscedastic with the heteroscedasticity p-value of 57 percent. The residuals are also normally distributed with the p-value of Jarque-Bera test of 76 percent. The implication is that the model is good for prediction because it satisfied all the assumptions of OLS and can be useful for prediction and policy purposes.

\subsection{Stability test}

Stability test is to show if the parameters are stable over time. The test is conducted using CUSUM test as shown in figure 4.1 .

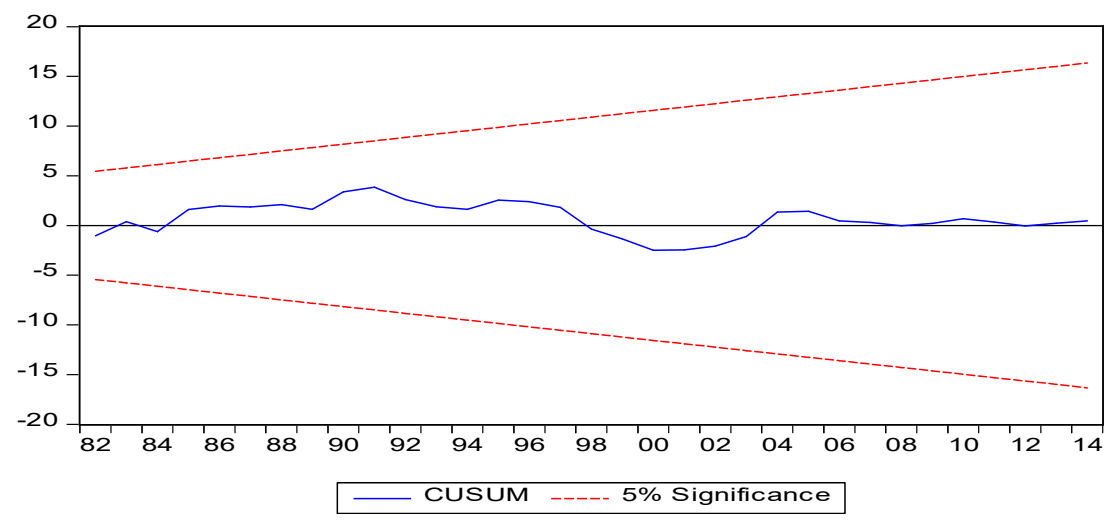

Figure 4.1: Stability test using CUSUM test

Source: Author computed using Eviews 10 
The decision rule is that if the model lies in between the 5 percent level of significance, then the model parameters are stable. Figure 4.1 showed that the parameters are stable. Figure 4.2 showed the CUSUM square test which showed that even when the regression is changed or subject to shocks, the parameters are stable over time.

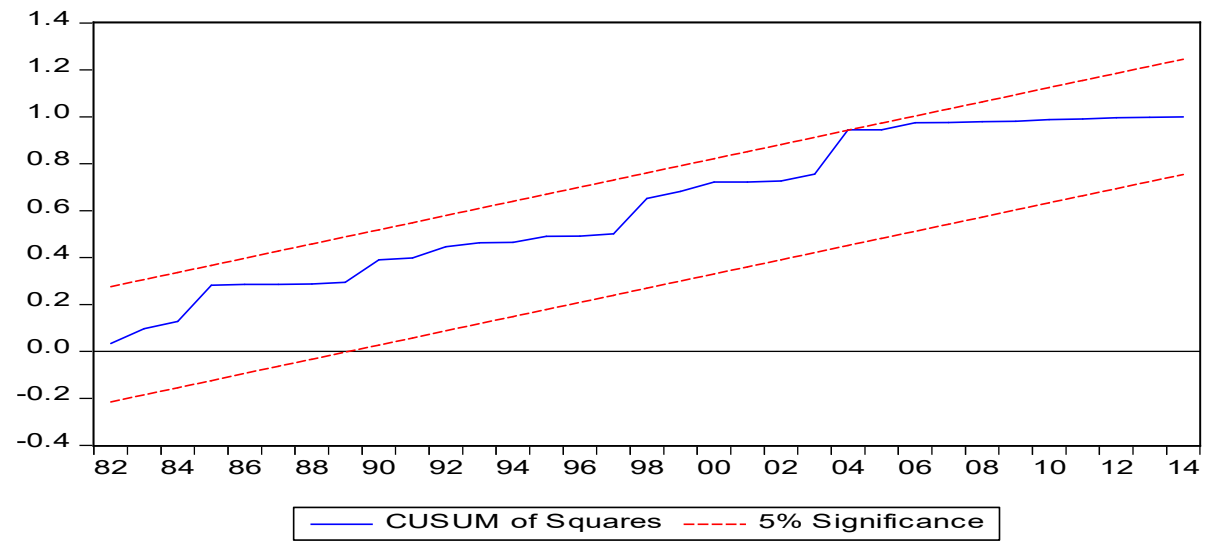

Figure 4.2: Parameter stability test using CUSUM of squares

Source: Author computed using Eviews 10

The combination of the results of residual diagnostic and the stability test makes the model quite reliable and good for both forecast and policy analysis.

\subsection{Conclusion and Policy Recommendations}

This work has examined the impact of supply of and demand for electricity on economic growth in Nigeria. It has been revealed from the results that the market forces of demand and supply of electricity have positive relationship with economic growth in the short run but not statistically significant. It was also revealed that they have a very strong impact on economic growth in the long run. On the basis of these findings, the following policy recommendations are put forward:

i. There should be deliberate policies that will encourage more private participation both at the generation, transmission and distribution. The current liberalization is still heavily controlled by the government and it limits adequate generation and distribution.

ii. Policies that will encourage off-grid supply should be put in place and cost of permit should be lowered to incentivize the private participation in the power sector.

iii. Electricity tariffs should be lowered to encourage more consumption and willingness of consumers to connect and pay.

iv. Adequate metering should be made available for both residential and industrial consumption to mitigate illegal connection and encourage pay as you go.

\section{References}

Abdisa (2018). Power outages, economic cost, and firm performance: Evidence from Ethiopia. Utilities Policy, $53,111-120$.

Adenikinju, A. F. (2003). Electric infrastructure failures in Nigeria: a survey-based analysis of the costs and adjustment responses. Energy Policy, 31(14), 1519-1530. 
Ariyo, D. (1999). Small firms are the backbone of the Nigeria economy. Africa Economic Analysis.

Awoyinfa, S. (2018). Nigeria needs 180,000MW to enjoy stable power supply. The Punch Online. Retrieved from doi https://punchng.com/nigeria-needs-180000mw-to-enjoy-stable-power-supply/

Cole, M., Elliot, R., Occhialli, G. and Strobi, E. (2018). Power outages and firm performance in SubSaharan Africa. Journal of Development Economics, 134, 150-159.

Esiedesa, O. (2021). Power generation falls further by $27 \%$ to $3,567 \mathrm{MW}$. https://www.vanguardngr.com/2021/04/power-generation-falls-further-by-27-to-3567mw/

Faisal, F., Tursoy, T. and Ercantan, O. (2017). The relationship between energy consumption and economic growth: Evidence from non-Granger causality test. Procedia Computer Science 120 (2017) 671-675.

Ihua, B. (2005). Critical challenges limiting small business performance in Nigeria: an exploratory investigation. International Journal of Business and Globalization. 9(2), 171-185.

Iyke, B. N. (2014). Electricity Consumption, Inflation, and Economic Growth in Nigeria: A Dynamic Causality Test. MPRA Paper No. 70001.

Kareem, R., Hakeem, B. , Kamilu, R. and Bashir, N.O. (2014). Econometric Analysis of Electricity Consumption, Capacity Utilization and Economic Growth in Nigeria: A Disaggregated Analysis. Journal of Economics and Sustainable Development, 5(4), 170- 178.

Kasperowicz, R. (2014). Electricity Consumption and Economic Growth: Evidence from Poland. Journal of International Studies, 7(1), 46-57.

Lugman, M., Hag, M. and Ahmad, I. (2021). Power Outages and Technical Efficiency of Manufacturing Firms: Evidence from Selected South Asian Countries. International Journal of Energy Economics and Policy, 11(2), $133-140$.

Magongo, T. and Sacolo, T. (2018). The economic costs of electrical power outages in Eswatini. African Review of Economics and Finance 10(2), 97-119.

Mezghani, I and Hedi, H. B. (2016). Energy consumption and economic growth: An empirical study of the electricity consumption in Saudi Arabia. Renewable and Sustainable Energy Reviews, 75, 145-156.

Ogundipe, A.A. and Apata, A. (2013). Electricity Consumption and Economic Growth in Nigeria. Journal of Business Management and Applied Economics, 2(4), 1-14.

Okorie, D. I. and Manu, S. A. (2016). Electricity consumption and economic growth: the Nigerian case. International Journal of Current Research, 8(12), 44008-44017.

Omay, T. Hasanov, M. and Ucar, N. (2014). Energy Consumption and Economic growth: Evidence from nonlinear Panel Cointegration and causality tests. Applied Econometrics, 34(2), 36-40.

Sambo, A. S. (2008). Matching Electricity Supply with Demand in Nigeria. International Association for Energy Economics, National Workshop on the Participation of State Governments in the Power Sector: Fourth quarter, 2008. 32-36.

Sambo, A. S., Garba, B., Zarma, I. H. and Gaji, M. M. (2010). Electricity Generation and the Present Challenges in the Nigerian Power Sector. Abuja: Nigeria Energy Commission of Nigeria. 